\section{Carotid endarterectomy guidelines}

The AAN article by Chaturvedi et al. updates the evidence for indications for carotid endarterectomy. Carotid endarterectomy is recommended for recently symptomatic patients with severe (70 to $99 \%$ ) internal carotid stenosis. For moderate (50 to 69\%), symptomatic stenosis, additional clinical and angiographic factors enter the decisions.

see page 794

\section{Pregnancy outcomes during INF beta treatment in MS}

Sandberg-Wollheim et al. review data on the outcome of 69 pregnancies in relation to IFN beta-1a therapy; 41 occurred in those exposed to IFN during pregnancy. Of the 31 in utero exposures that were not terminated electively, 21 produced healthy infants. The rate of pregnancy loss (9/31) was not significantly different from general population estimates.

see page 802

In a prospective controlled study of pregnant women with MS, Boskovic et al. found evidence suggesting that discontinuation of IFN beta increases the risk of pregnancy loss. These results are concordant with data in primates, suggesting that current recommendations to discontinue IFN beta prior to and during pregnancy are appropriate.

see page 807

In the editorial on these two articles, Waubant and Sadovnick recommend discontinuing disease modifying therapies for MS prior to initiating pregnancy, but find no evidence to support aborting pregnancies conceived during IFN $\beta$ use.

see page 788

\section{Effect of simulator training on driving after stroke: A RCT}

Driving ability is impaired after stroke. Akinwuntan et al. investigated the effects of two driving training methods after stroke. Following 15 hours training in the subacute phase, significantly more experimental subjects as compared to controls passed an official driving test 6 months after stroke. Simulator-based training was better than driving-related cognitive training, especially for well-educated and less disabled stroke patients.

see page 843

There is a Patient Page on this topic:

www.neurology.org

786 Copyright $\odot 2005$ by AAN Enterprises, Inc.

\section{$S M N$ genotypes producing less SMN protein contribute to outcome of ALS}

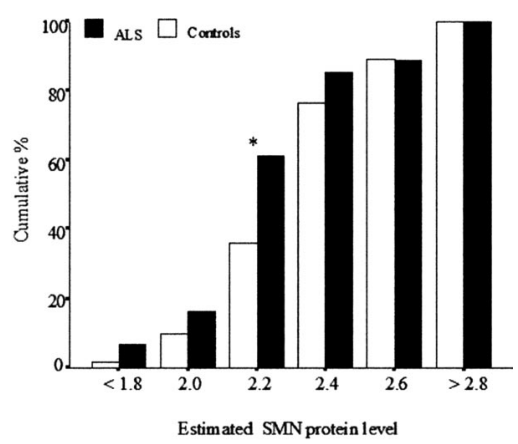

Median survival in lowest category $=2.5$ years, median survival in highest category $=3.4$ years $(p=0.003)$.

Veldink et al. studied 242 patients with sporadic ALS to determine whether SMN genotypes are associated with susceptibility to and severity of ALS. The combined determination of SMN1 and SMN2 copies also allowed for an estimation of the level of SMN protein for each patient. They found that $S M N$ genotypes producing less SMN protein increase susceptibility to and severity of ALS.

see page 820

\section{Inflammatory and TGF $\beta$ pathways in Duchenne muscular dystrophy}

By expression profiling muscles from fetopsies, 8- to 10-month-old infants, and symptomatic patients with DMD, Chen et al. found early involvement of activated tissue dendritic cells, expression of toll-like receptor 7 , and strong induction of NF-kB in DMD muscles, while the TGF $\beta$ pathway was strongly induced later in the disease.

see page 826

\section{Prognosis and treatment after stroke in the elderly}

Kaplan et al. found that among 546 ischemic stroke survivors $>65$ years old, stroke recurrences were more frequent than coronary events within the year following stroke. After the first year, rates of coronary events and stroke recurrences were similar. Secondary prevention therapies were underused, particularly in older patients, women, and low-income individuals.

see page 835 


\section{Antihypertensives and ischemic stroke severity}

In an observational study, Ovbiagele et al. found no difference between the effects of angiotensin IIformation increasing agents vs angiotensin II-formation suppressing agents on ischemic stroke severity. However, prestroke use of an antihypertensive agent was associated with reduced severity of incident ischemic stroke.

see page 851

\section{Completeness of stroke evaluation in men vs women}

Using the population-based Brain Attack Surveillance in Corpus Christi (BASIC), Smith et al. found that women were less likely to receive echocardiography and carotid evaluation than men despite controlling for explanatory variables.

see page 855

\section{Stroke recurrences in middle cerebral artery disease}

Kern et al. studied the long-term course of 102 patients with stenosis or occlusion of the middle cerebral artery. Symptomatic arterial disease at study entry was an independent predictor for recurrent cerebrovascular events, compared to a low recurrence rate in asymptomatic patients.

see page 859

\section{Diabetes associated with brain atrophy}

Cerebral MRI scans were analyzed by Knopman et al. in 1,812 middle-aged and young elderly individuals. Among several cardiovascular risk factors, diabetes alone was associated with larger brain lateral ventricles. The findings provide a pathoanatomic link between diabetes and cognitive function changes in later life.

see page 876
Quality of life in Charcot-MarieTooth disease

Vinci et al. showed that CMT patients scored lower than normal in all aspects of QoL evaluated by the SF-36 questionnaire. Demyelinating and axonal forms were similarly affected.

see page 922

The editorial by Shy and Rose notes that there are a number of potentially useful treatments for CMT. As these agents move into full clinical trials, endpoints will be required to measure their effectiveness. OoL measures in clinical trials will be essential to obtain trial participants' views as to the effectiveness of an intervention. However, QoL does not invariably correlate with disease severity. Citing the "disability paradox" and "response shifts" as reasons for this lack of correlation, they noted that in some chronic diseases, e.g., quadriplegia from a cervical spinal cord injury, OoL measures may actually improve, without any physical improvement, long after the injury.

see page 790

\section{Adult onset dystonia: An inherited sensory disorder?}

Using spatial discrimination thresholds, O'Dwyer et al. found abnormalities in 12 of 49 unaffected family members from four multiplex families with primary torsion dystonia. Sensory abnormalities may detect asymptomatic disease.

see page 938

The editorial by Meunier and Hallett notes that this relatively simple clinical testing is able to detect subclinical abnormal spatial discrimination capability (SDT) in unaffected relatives of patients with a genetic form of late-onset cervical dystonia. The implication, that cannot be currently verified, is that these persons are non-manifesting gene carriers. Testing SDT is easy to perform, safe, and noninvasive and could be useful in screening of pedigrees. Sensory abnormalities likely represent an endophenotype of dystonia. Assuming that this is the case, the lack of symptoms in a large number of dystonia-endophenotype carriers indicates that other factors are necessary for dystonia to develop: trauma, infection, high fever, and repetitive activation are possible candidates.

see page 792 


\section{Neurology}

September 27 Highlights

Neurology 2005;65;786-787

DOI 10.1212/01.wnl.0000182167.59689.ff

This information is current as of September 26, 2005

\section{Updated Information \&}

Services

Permissions \& Licensing

Reprints including high resolution figures, can be found at: http://n.neurology.org/content/65/6/786.full

Information about reproducing this article in parts (figures,tables) or in its entirety can be found online at:

http://www.neurology.org/about/about_the_journal\#permissions

Information about ordering reprints can be found online:

http://n.neurology.org/subscribers/advertise

Neurology ${ }^{\circledR}$ is the official journal of the American Academy of Neurology. Published continuously since 1951, it is now a weekly with 48 issues per year. Copyright. All rights reserved. Print ISSN: 0028-3878. Online ISSN: 1526-632X.

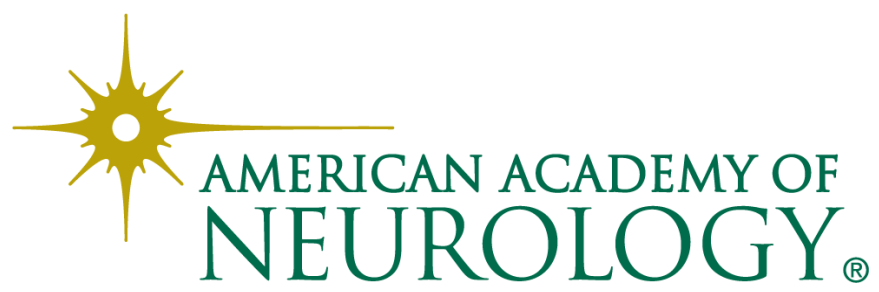

